\title{
SHORT RESEARCH NOTES
}

\section{Leaf-clearing and staining techniques for the observation of conidiophores in the Phyllactinioideae (Erysiphaceae)}

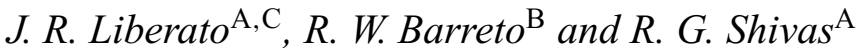 \\ A Department of Primary Industries and Fisheries, Plant Pathology Herbarium, 80 Meiers Road, \\ Indooroopilly, Qld 4068, Australia. \\ ${ }^{B}$ Universidade Federal de Viçosa, Departamento de Fitopatologia, 36571-000, Viçosa, MG, Brazil. \\ ${ }^{\mathrm{C}}$ Corresponding author. Email: jose.liberato@dpi.qld.gov.au
}

Abstract. Some whole leaf-clearing and staining techniques are described for the microscopic observation of the origin of powdery mildew conidiophores, whether from external mycelium or internal mycelium, emerging through stomata. These techniques enable separation of the two genera, Oidiopsis and Streptopodium, in the Erysiphaceae.

Additional keyword: Ovulariopsis.

The powdery mildews (Erysiphaceae: Ascomycota) are biotrophic plant pathogenic fungi that are classified in two subfamilies, the Erysiphoideae and the Phyllactinioideae (Braun 1987). The Erysiphoideae has an exclusively external mycelium and anamorphic states belonging to the genus Oidium (Braun 1999; Braun and Takamatsu 2000; Braun et al. 2002), that has conidia which are ellipsoid, ovoid, cylindrical or doliiform, produced either singly or in chains. The Phyllactinioideae includes the genera Phyllactinia (anamorph Ovulariopsis), Leveillula (anamorph Oidiopsis), and Pleochaeta (anamorph Streptopodium) which typically have hemiendophytic (partly external and partly internal) mycelia with conidia that are lanceolate, clavate, obclavate or cylindrical and usually produced singly (Braun 1987; Boesewinkel 1980).

Recently, electron microscopy and molecular studies have led to significant changes in the taxonomy of the Erysiphaceae. Consequently, the morphological characteristics of the anamorphs are now regarded as fundamental to the delimitation and phylogenetic placement of the holomorph. The accurate identification of a powdery mildew anamorph allows the associated teleomorph to be predicted in the absence of its ascomata (Braun et al. 2002). This is important, as anamorphic stages of the Erysiphaceae are the predominant form of the powdery mildew fungi in the tropics and subtropics worldwide (Braun et al. 2002).

Oidium can be differentiated from anamorphs of Phyllactinioideae by the production of comparatively smaller sized conidia of a different shape and an exclusively external mycelium. Anamorphs of Phyllactinioideae have hyphae that penetrate the leaf through stomata, forming internal mycelium (Braun 1987; Boesewinkel 1980).

There are two basic differences between Phyllactinioideae anamorphs belonging to Ovulariopsis or Oidiopsis. First, Oidiopsis has dimorphic conidia. This term is commonly used to designate clear morphological differences between the first conidium (primary conidium) formed on a conidiophore and all others formed subsequently (secondary conidia) in the powdery mildews of Phyllactinioideae. Its primary conidium is apically pointed or lanceolate whereas secondary conidia are ellipsoid to cylindrical with rounded to truncate apices. Ovulariopsis has only monomorphic conidia (there are no differences between primary and secondary conidia), mostly subclavate to clavate, but never lanceolate. The second difference is that conidiophores of Oidiopsis originate from the internal mycelium emerging through the stomata, which contrast with Ovulariopsis that has conidiophores arising directly from the external mycelium (Braun 1987).

Ovulariopsis and Oidiopsis are very closely related (Mori et al. 2000). Streptopodium is regarded by Gorter and Eicker (1983) as an intermediate between them, having characteristics of those two genera, namely conidia that are dimorphic, as does Oidiopsis, but conidiophores originating from the external mycelium, as does Ovulariopsis (Liberato et al. 2004). 
The microscopic observation of conidiophores arising from the internal mycelium, through stomata, is difficult. This is a cause of misidentification between Oidiopsis and Streptopodium. This feature is well observed under scanning electron microscopy, but it is impractical for routine identification. In order to observe the origin of conidiophores in the Phyllactinioideae, it was tried and then modified the whole leaf clearing and staining technique, proposed by Bruzzese and Hasan (1983) for rust studies, as well as two other techniques used in host-pathogen interaction studies (White and Baker 1954; McLean and Byth 1981). Modifications of these techniques were aimed at reducing the processing time and the number of toxic chemicals used. Five techniques are hence described below.

The following specimens were used to test these techniques: (a) dried specimens: Oidiopsis anamorph of Leveillula taurica on Carica papaya: BRIP 2128, 2130,2133, and 21065, IMI 226117a, VPRI 19420; on Euphorbia spp.: BRIP 13824, 16890, 20064, 23464, 25568, 26529, 26732, and 44907, VPRI 17917 and 20208; on Ruta graveolens: VIC 26484 and 26492; Ovulariopsis papayae on C. papaya: NH 924; Pleochaeta turbinata on Platycyamus regnellii: IACM 4541; Streptopodium caricae on $C$. papaya: IBI 11814, VIC 22182, and 22187; (b) fresh specimens: S. caricae on C. papaya: VIC 26548, 26549, 26550, 26552 and 26543; Streptopodium sp. on Tabebuia serratifolia: VIC 26551 and 26559.

\section{Technique 1 (modified from Bruzzese and Hasan 1983)}

Solution A: successively add the series of compounds given below in a flask with continuous agitation with a magnetic stirrer until all solids dissolve: $30 \mathrm{~mL} 95 \%$ ethanol; $15 \mathrm{~mL}$ chloroform; $12.5 \mathrm{~mL} 90 \%$ lactic acid; $45 \mathrm{~g}$ chloral hydrate; $0.06 \mathrm{~g}$ aniline blue.

Solution B: $50 \mathrm{~g}$ chloral hydrate in $20 \mathrm{~mL}$ of distilled water. Note: both solutions must be prepared in a fume hood and disposable gloves should be worn.

Leaf pieces around $0.25-0.5 \mathrm{~cm}^{2}$, infected with powdery mildew, were submerged in solution A in stoppered glass vials at room temperature for $48 \mathrm{~h}$ and then washed rapidly in distilled water and left in solution B for $24 \mathrm{~h}$. The leaf portions were then removed, washed rapidly in distilled water and mounted on microscope slides in $85 \%$ lactic acid.

The following specimens were used to test this technique: (a) dried specimens: BRIP 2130, 2133, 16890, 20064, 21065, 23464, 26732, 44907; IBI 11814, IMI 226117a, IACM 4541, NH 924, VIC 22182, 22187, 26484 and 26492; (b) fresh specimens: VIC 26543, 26548, 26549, 26550, 26551, 26552 and 26559.

\section{Technique 2}

Only solution B of the Bruzzese and Hasan (1983) method was used (see above). Leaf pieces, infected with powdery mildew, were immersed in solution B in stoppered glass vials at room temperature, for $6-48 \mathrm{~h}$, washed rapidly in distilled water, and mounted on microscope slides in $85 \%$ lactic acid with $1 \mathrm{~g} / \mathrm{L}$ aniline blue. In order to reduce processing time, this technique was modified by placing stoppered glass vials containing leaf pieces immersed in solution $\mathrm{B}$ in a water bath at $60^{\circ} \mathrm{C}$ for $1 \mathrm{~h}$. The leaf pieces were then mounted on microscope slides in $85 \%$ lactic acid with $1 \mathrm{~g} / \mathrm{L}$ aniline blue.

The following dried specimens were examined: BRIP 2128, 16890, 13824, 25568, 26529 and VPRI 20208.

Technique 3 (modified from McLean and Byth 1981)

Leaf pieces, infected with powdery mildew, were immersed in a mixture of $100 \%$ acetic acid and absolute ethanol $(1: 1, \mathrm{v} / \mathrm{v})$, in stoppered glass vials at room temperature, for 6-48 h, washed rapidly in distilled water, and mounted on microscope slides in $85 \%$ lactic acid with $1 \mathrm{~g} / \mathrm{L}$ aniline blue. To reduce the processing time, a modification of this technique was used: the stoppered glass vials with leaf pieces in the solution were placed in a water bath at $60^{\circ} \mathrm{C}$ for $1 \mathrm{~h}$. The leaf pieces were then mounted on microscope slides in $85 \%$ lactic acid with $1 \mathrm{~g} / \mathrm{L}$ aniline blue.

The following dried specimens were examined: BRIP 13824, 16890, 25568, 26529 and VPRI 17917.

\section{Technique 4 (White and Baker 1954)}

Leaf pieces, infected with powdery mildew, were immersed in $10 \mathrm{~mL}$ of lacto-glycerol $(100 \mathrm{~mL} 85 \%$ lactic acid, $200 \mathrm{~mL}$ glycerol, $100 \mathrm{~mL}$ distilled water) containing $10 \mathrm{~g} / \mathrm{L}$ cotton blue in flasks and then heated on a hot plate until boiling and allowed to simmer for $3 \mathrm{~min}$ in a fume hood. The flask was removed from the hot plate and allowed to cool; the leaf pieces were removed and then gently rinsed in distilled water before mounting on microscope slides in $85 \%$ lactic acid.

Dried specimen BRIP 16890 was subjected to this treatment.

\section{Technique 5 (modified from Shin and La 1993)}

Leaf pieces, infected with powdery mildew, were placed on a slide and covered with a drop of $85 \%$ lactic acid with $1 \mathrm{~g} / \mathrm{L}$ aniline blue and a coverslip. The microscope slide was held carefully above a gas burner flame until the mounting medium started to boil and allowed to simmer for 5-20 s. After cooling, the coverslip was removed and the leaf piece was transferred to another microscope slide and mounted in a drop of $85 \%$ lactic acid with $1 \mathrm{~g} / \mathrm{L}$ aniline blue. As powdery mildew fungi of subfamily Phyllactinioideae usually infect the abaxial leaf surface, care was taken to mount the colonised surface face up on the microscope slide.

Dried specimens BRIP 13824 and VPRI 19420 were treated this way.

Technique 1 gave good results for all specimens examined with the exception of IACM 4541. The host plant in this 
specimen has long trichomes that did not allow the coverslip to sit properly on the leaf surface. This technique has two problems. First the leaf is stained blue as well as the fungus, making distinction of fungal structures and interpretation of conidiophore origin difficult. Second, the processing time is rather long (3 days). Despite these disadvantages, the use of this technique has already proven useful for differentiation between Oidiopsis (Fig. 1A) and Streptopodium (Fig. 1B) (Liberato et al. 2004). It also has the advantage of allowing a delay in mounting the specimens since it is possible to keep the leaf pieces in solution B for several days, without damaging them.

Technique 2 reduced the processing time and the number of toxic compounds (only chloral hydrate was used). Some specimens were examined after $6 \mathrm{~h}$, and the others after 24 or $48 \mathrm{~h}$. Placement of the specimen in a water bath at $60^{\circ} \mathrm{C}$ for $1 \mathrm{~h}$ saved time and did not affect the results. This technique gave the best results (Fig. 1C). It is now used routinely in herbarium BRIP.

Technique 3 is an alternative to technique 2, and uses two chemicals, acetic acid and ethanol, commonly found in plant pathology laboratories. Its results were almost as good as technique 2 (Fig. 1D). Placement of the specimen in a water bath at $60^{\circ} \mathrm{C}$ for $1 \mathrm{~h}$ saved time and did not affect the results.

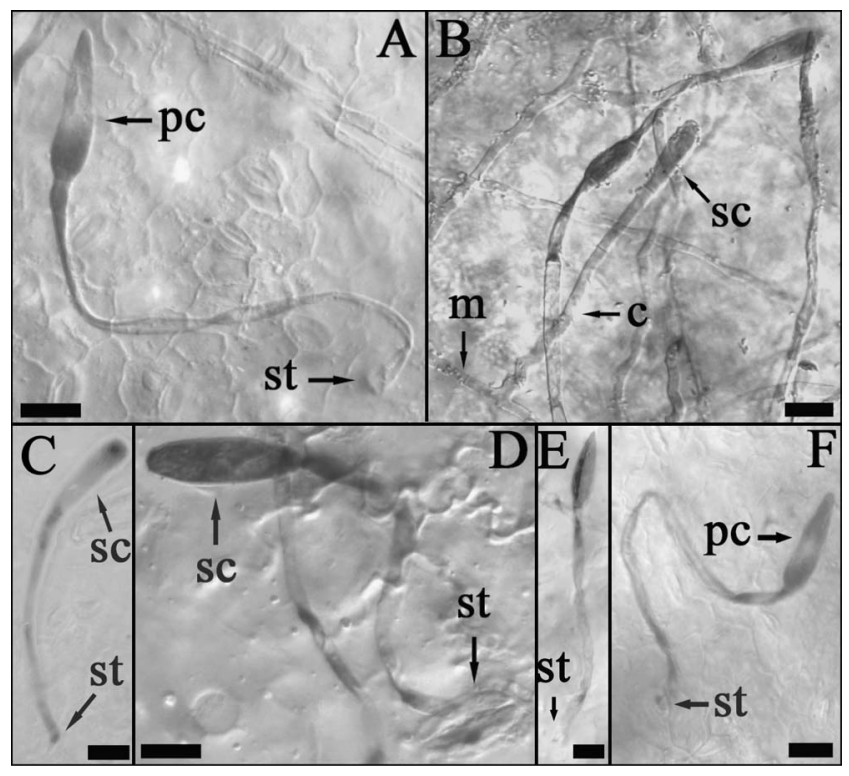

Fig. 1. (A) Technique 1. Oidiopsis anamorph of Leveillula taurica on Carica papaya (BRIP 21065). Conidiophore arising from internal mycelium through stoma (st) with primary conidium (pc). (B) Technique 1. Streptopodium caricae on C. papaya (IBI 11814). Conidiophore (c) arising from external mycelium $(\mathrm{m}) .(C-F)$ Oidiopsis anamorph of $L$. taurica. Conidiophore arising through stoma with primary or secondary conidium (sc). (C) Technique 2 on Euphorbia heterophylla (VPRI 20208). (D) Technique 3 on E. cyathophora (BRIP 16890). (E) Technique 4 on E. cyathophora (BRIP 16890). (F) Technique 5 on C. papaya $($ VPRI 19420) $(\mathrm{Bar}=20 \mu \mathrm{m})$.
Technique 4 enabled the tracing of the origin of conidiophores (Fig. 1E). However, this technique has limitations; it is time consuming and not as reliable as the previous methods since the simmering dislodged some fungal conidiophores and spores from the leaf surface.

Technique 5 is relatively fast, simple to use and also enabled the origin of conidiophores to be traced (Fig. $1 F$ ) but the quality of the results depended significantly on the host species and simmering time. A short simmering time might be insufficient to clear the leaf, and a longer period of simmering often dislodged fungal conidiophores and spores from the leaf surface.

All techniques allowed the observation of the origin of conidiophores using a light microscope. It is important to note that observation of several conidiophores is required since a small percentage of the conidiophores of Oidiopsis may arise from external mycelium (Homma et al. 1981) which might lead to the mistaken conclusion that the specimen is a Streptopodium sp.

There are many other techniques described in the literature. These were not tested here because they involve the use of toxic compounds such as phenol (Ram and Nayyar 1978) and chlorine gas (Janes 1962) or because they are similar to the techniques described in this study (Shipton and Brown 1962; Koga and Kobayashi 1980; Keane et al. 1988).

\section{Acknowledgements}

J. R. Liberato acknowledges financial support from the Brazilian Fundação Coordenação de Aperfeiçoamento de Pessoal de Nível Superior (CAPES).

\section{References}

Boesewinkel HJ (1980) The morphology of the imperfect states of powdery mildews (Erysiphaceae). Botanical Review 46, $167-224$.

Braun U (1987) A monograph of the Erysiphales (powdery mildews). Beiheft zur Nova Hedwigia 89, 1-700.

Braun U (1999) Some critical notes on the classification and generic concept of the Erysiphaceae. Schlechtendalia 3, 48-54.

Braun U, Cook RTA, Inman AJ, Shin H-D (2002) The taxonomy of the powdery mildew fungi. In 'The powdery mildews: a comprehensive treatise'. (Eds RR Bélanger, WR Bushnell, AJ Dik, TLW Carver) pp. 13-55. (APS Press: St Paul)

Braun U, Takamatsu S (2000) Phylogeny of Erysiphe, Microsphaera, Uncinula (Erysipheae) and Cystotheca, Podosphaera, Sphaerotheca (Cystotheceae) inferred from rDNA ITS sequences — some taxonomic consequences. Schlechtendalia 4, 1-19.

Bruzzese E, Hasan S (1983) A whole leaf clearing and staining technique for host specificity studies of rust fungi. Plant Pathology 32, 335-338.

Gorter GJMA, Eicker A (1983) Uncinula polychaeta, Pleochaeta and Streptopodium in South Africa. Transactions of the British Mycological Society 81, 398-401.

Homma Y, Takahashi H, Arimoto Y, Ishikawa T, Matsuda I, Misato T (1981) Studies on pepper powdery mildew. II. Conidiophore emergence and conidial formation on pepper leaf. Annals of the Phytopathological Society of Japan 47, 143-150. 
Janes BS (1962) Leaf-clearing technique to assist fungal spore germination counts. Nature 193, 1099-1100.

Keane PJ, Limongiello N, Warren MA (1988) A modified method for clearing and staining leaf-infecting fungi in whole leaves. Australasian Plant Pathology 17, 37-38.

Koga H, Kobayashi T (1980) A whole-leaf clearing and staining technique to observe the invaded hyphae of blast fungus and host responses in rice leaves. Annals of the Phytopathological Society of Japan 46, 679-681.

Liberato JR, Barreto RW, Louro RP (2004) Streptopodium caricae sp. nov., with a discussion of powdery mildews on papaya, and emended descriptions of the genus Streptopodium and Oidium caricae. Mycological Research 108, 1185-1194. doi: 10.1017/ S0953756204000991

McLean RJ, Byth DE (1981) Histological studies of the pre-penetration development and penetration of soybeans by rust, Phakopsora pachyrhizi Syd. Australian Journal of Agricultural Research 32, 435-443. doi: 10.1071/AR9810435
Mori Y, Sato Y, Takamatsu S (2000) Evolutionary analysis of the powdery mildew fungi using nucleotide sequences of the nuclear ribosomal DNA. Mycologia 92, 74-93.

Ram HYM, Nayyar VL (1978) A leaf-clearing technique with a wide range of applications. Proceedings of the Indian Academy of Sciences, B 87, 125-127.

Shin H-D, La Y-J (1993) Morphology of edge lines of chained immature conidia on conidiophores in powdery mildew fungi and their taxonomic significance. Mycotaxon 46, 445-451.

Shipton WA, Brown JF (1962) A whole-leaf clearing and staining technique to demonstrate host-pathogen relationships of wheat stem rust. Phytopathology 52, 1313.

White NH, Baker EP (1954) Host pathogen relations in powdery mildew of barley. 1. Histology of tissue reactions. Phytopathology 44, $657-662$

Received 18 October 2004, accepted 1 February 2005 